\title{
ENHANCING MATHEMATICS STUDENTS' MENTAL COMPUTATION IN CALCULATING PERCENTAGE BY USING THE BUBBLE METHOD
}

\author{
Nor Halimah Aminah Muhammad Nur Lubis ${ }^{1}$, Khairul Amilin Tengah ${ }^{2}$, \\ Masitah Shahrill ${ }^{3}$ and Elvynna Leong ${ }^{4}$ \\ ${ }^{1,2,3}$ SultanHassanalBolkiah Institute of Education, Universiti Brunei Darussalam, Brunei \\ ${ }^{4}$ Faculty of Science, Universiti Brunei Darussalam, Brunei
}

\begin{abstract}
As students progressed from primary to secondary school, they are exposed to the constant use of calculators in Mathematics. Due to this reason, some of them are becoming too comfortable and too dependent on calculator even for simple arithmetic. Hence, this study was conducted to promote mental computational skills amongst secondary students by using the Bubble Method. A total of 44 mathematics students from two different schools were selected to be the participants of this study and were involved in intervention lessons using the Bubble Method. Based on the analysis result of pre-test and post-test, administered before and after the intervention respectively, 11 students were selected for further interview. Based on the findings, the effect of the students' performance in calculating percentage has been found to be not statistically significant using the Bubble method, however, all the students who were interviewed agreed that the Bubble Method improved their mental computational skill.
\end{abstract}

Keywords: Bubble Method, Mental Computation, Percentage, Mathematics

\section{Introduction}

In order to provide holistic education to achieve fullest potential for all, and to fulfil the needs and challenges of the social and economic development of the $21^{\text {st }}$ Century for the young generation and develop $21^{\text {st }}$ century skills amongst students, Brunei Darussalam's (hereafter referred to as Brunei) Ministry of Education introduced a new educational system in 2008 known as the National Education System for the $21^{\text {st }}$ Century or Sistem Pendidikan Negara Abad ke-21, SPN 21(Ministry of Education, 2013).The curriculum in the SPN21 education system were organised based on several factors including toemphasisis on essential skills, knowledge and understanding, particularly in the nine specific learning areas, including mathematics,. One of the skills that is categorised under the essential skills is numeracy skills. Hence, to adapt to this curriculum, a study was conducted to enhance the numeracy skills for secondary students.

Teachers play an important role in education. However, being a teacher in this century is challenging, particularly to experienced teachers who are set on their practicing teacher-centred approach. In order to enact the SPN21 system, they have to be aware of and adaptable to the current method of teaching that cater the learning style of the current young generation. This also applies to new teachers and pre-service teachers who were brought up and taught with the teacher-centred approach. The way a teacher was once taught is a factor that influenced the way the teacher teaches (Cruickshank et al. 2009). Hence, all teachers, experienced or amateur, have to keep an open mind and be receptive to the $21^{\text {st }}$ century trends and cultures in teaching and learning.

\section{Need and significance of the study}

Students are early exposed to mental computation from primary level. They would perform simple calculation

Corresponding Author:Nor HalimahAminah Muhammad NurLubis/ms.norhalimah@ gmail.com 
mentally or written, but as they advanced to secondary level, with the introduction of calculator andfrequent used in many math lessons, most of them are inclined to use calculators to calculate simple addition, multiplication or arithmetic as they progress.

In traditional teaching in Brunei, when introducing a new topic that involves the use of formula(s), mojority teacherstend to start by introducing a formula to the students which they have to memorize and use to perform a written algorithm in order to solve mathematics problems. The teacher would follow-up with few worked-out examples using that given formula and provide similar questions for the students to practice by themselves. With this practice and drilling, some students are be able to remember and grasp the concept of the formula they learned. However, SPN21 emphasises on teaching the concept before the students are introduced to the formula so that they will have better understanding on the formula, which this study is based on.

This study focuses on percentage as it can be easily related to real world context and is commonly used in other subject area. This is supported by McIntosh and Dole (2000) who state "Percent is one topic within the mathematics curriculum that is frequently used and applied in other subject areas as well as beyond the classroom".

This study exposes the students to mental computation and thus encourage them to be less dependent on calculator. To make this mental computation skill as a life skill, this study may help students compute percentages mentally in real life situations, where we do not always have calculator in our hands.

\section{Purpose of the study}

The Bubble Method will focus on and promote mental computation skill among secondary school students, encouraging less reliance on calculator and enhance their skills in computing mentally. In addition, this study will also investigate how effective the Bubble Method as an alternative method of in calculating percentage, in addition to prior methods introduced before.

\section{Theoretical Framework of the Research Study}

In order to guide and ease the process of this research, the theoritical framework shown in Figure 1 wasused as a guidence to carry out the study. With the Bubble Method, the lesson will be focusing on mental computation, and to enhance their knowledge on percentages by using the students' prior knowledge on addition, subtraction and division. This method also uses students' previous knowledge on certain topic and build up a new knowledge on another topic and hence they would understand the concept or meanings behind it. 


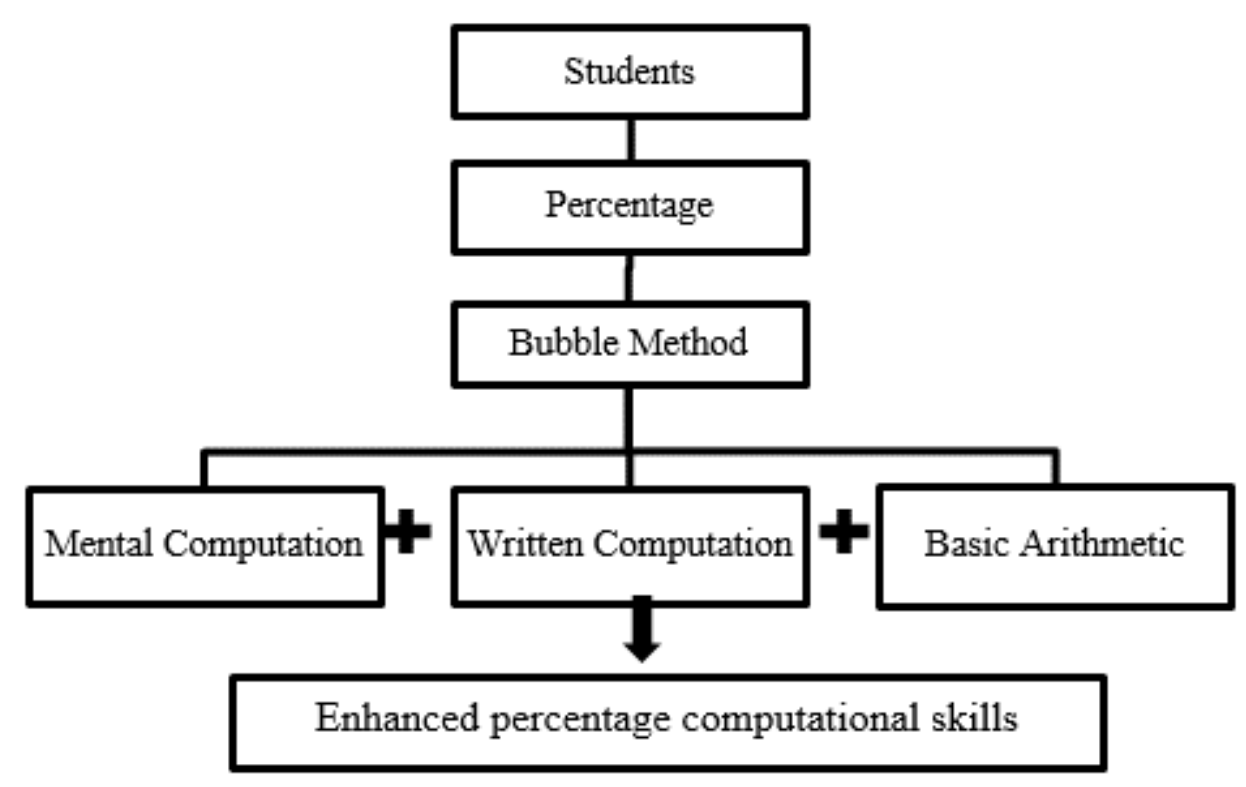

Figure 1 Theoretical Framework of Study

These research questions were used to guide this study:

Research Question 1: What is the relationship between students' achievement and the use of Bubble Method in calculating percentage?

Research Question 2: What are the students' perception of Bubble Method in terms of enhancing their mental computation and calculating percentage?

\section{Review of Literature}

\section{Mental Computation}

Mental computation can be defined as the process of calculation without the use of any external calculator or recording device (Reys et al.1995). According to Hartnett (2007), mental computation has been the focus of a major shift in mathematics education in many parts of the world as it is the mathematical skill that is applicable to real life situation. Thus, mental computation should be focused asan essential skill required in education.

Rogers (2009) reminded that mental computation should not be confused with mental arithmetic as these two are not the same educationally, despite both requiring mental thinking and independent use of calculator. He explained that mental computation is focused on promoting children's understanding and metacognition, while in mental arithmetic, speed matters and relies mostly on memorisation. McIntosh (2006) stated his concern that due to the speed and memorisation, it will make students slightly more neurotic about numbers. On the other hand, mental computation can be associated with written computation as these two are involved in mathematical computation (Rogers, 2009).

In school, the constant use of calculators to simplify solving mathematical problems have lead to the discouragement of mental computation. Hence, this research would help in instilling and strengthening mental 
calculation skill within the students as this skill is also considered as higher-level mathematic thinking skill (Reys et al. 1995).

\section{Problems in Learning Percentage}

One of the topics in mathematics curriculum that caused learning difficulties amongst the students is percentage (Parker and Leindhardt, 1995, Kachapova and Kachapova, 2011). Due to these common difficulty faced by students, Parker and Leindhart (1995) reviewed studies by other researchers and categorised students'common error in calculating percentage. First, students tend to ignore percentage sign where the students mistook percentage sign as a label, with no operational significance. In reality, percentage is a fraction out of a hundred and percentage sign is actually a sign that represents a denominator of a hundred. The second common error Parker and Leindhardt (1995) found was that even if the students knew that the percentage sign had operational significant, they made a numeratorrule error. Both these mistakes stemmed from the lack of understanding of the concept of percentage and blindly following the procedural steps in solving the problem.

To counter the learning problem of percentage, recent studies on percentages are mostly focused on investigating different effective strategies in teaching percentages (White et al. 2009, Kachapova and Kachapova, 2011, Watson and English, 2013). These strategies focused on the conceptual understanding of percentage and its application to real life situation. Since mental computation helps in students' understanding and metacognition, it would be a good study to investigate teaching strategy focusing on mental computation as an everyday life skill.

\section{Bubble Method}

In this study, the Bubble method used to teach percentage is a simplified chart used to calculate a percentage of any number. It does not involve fraction and hence the numerator rules mistakes can be easily avoided. In addition, the method requires students to write down the percentage sign, thus will reduce the chances of students making the ignore percentage sign mistake.

Thompson (2011) described Bubble Method as a step by step method for working out any percentage using easy mental maths methods such as dividing by 10 or 100; doubling and adding up. Therefore, with the Bubble Method, no calculator or minimal usage of calculator is required. The calculations and computations can be done mentally; the percentage/numbers will be divided by 2,10 , or 100 or it can also be composed by adding up or decompose by splitting certain percentage/number to a certain amount. Figure 2 shows a pictorial example of calculating percentage using the Bubble Method.

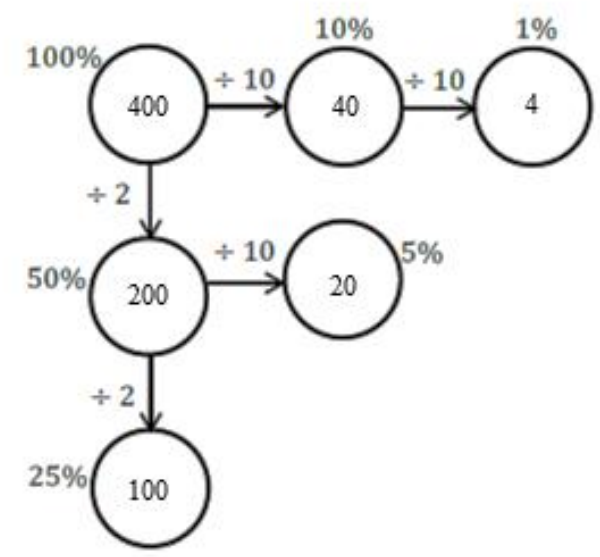

Figure 2 An example of calculating percentage using the Bubble Method 
The example in Figure 2 shows that to calculate 24\% of 400, start by entering 400 in the $100 \%$ bubble and work around the bubble by entering the values inside the bubble. Since $24 \%$ of 400 is not stated in the bubble, decompose $24 \%$ into $10 \%+10 \%+1 \%+1 \%+1 \%+1 \%$, which will give us 94 . Alternatively, we can use $25 \%$ $-1 \%(100-4)$

The process of decomposing numbers (McIntosh and Dole, 2006, Hartnett, 2007) and dividing by 2 (Hartnett, 2007, Wiggly, 2008) fall under the category of mental computation strategies. In addition, the researcher also considers that dividing numbers by 10 or 100 also falls under the same category since it can be done mentally.

In conclusion, the Bubble Method offers a solution to the problems commonly faced in percentage calculation and therefore, could increase the understanding of the concept of percentage. In addition, the method could help to strengthen the students' computation skill as it involves the use of mental computation which is essentially applied in real life calculation skills.

\section{Methodology}

This research adopted the mixed-mumods approach that combines both quantitative and qualitative approach (Mills, 2014). The two research questions stated in the introduction section were used to guide the study. Figure 3 is an illustration of the instrument used for collecting data for the above purpose.

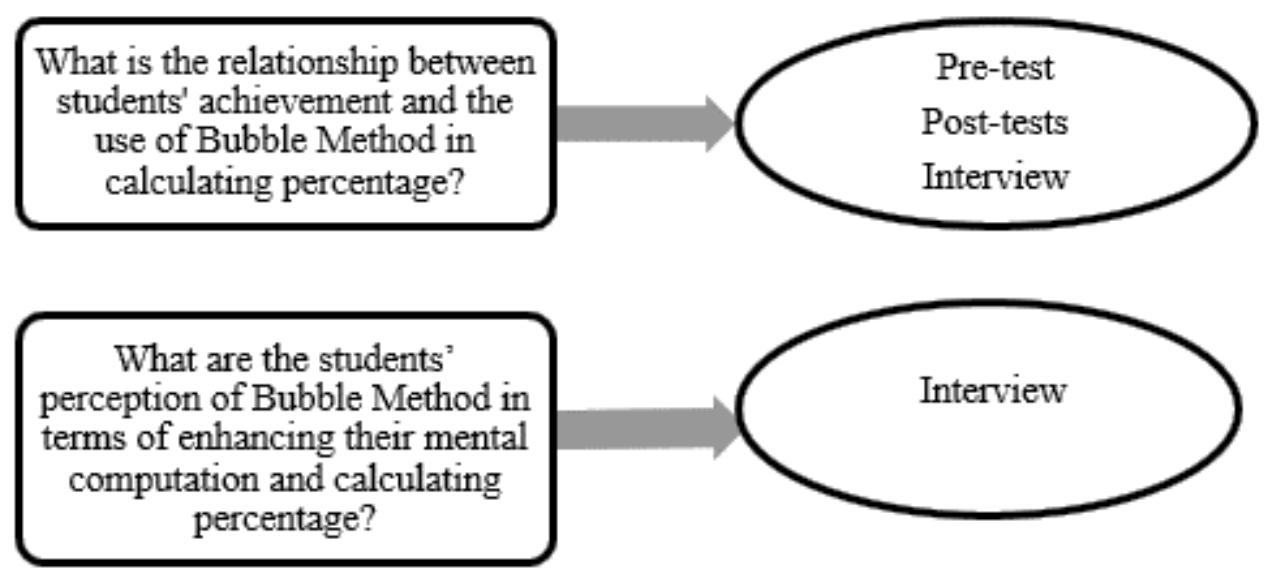

Figure 3 Instrument for collecting data

The participants involved for this study were Year 9 students from two secondary schools in Brunei; an all-boys and mixed gender school. The participants from all-boys school (Class A) consisted of 14 students, while two groups from the mixed gender school (Class B and C) consisted of 12 and 18 students respectively. The participants from the three categories comprised of different level of achievers. Class $\mathrm{A}$, the students were classified as low achievers, Class B consisted of high achievers and the students in Class $\mathrm{C}$ were a mixture of low and high achievers. Therefore, the total numbers of participants for the lesson intervention were 44 students.

In this study, interventionwas conducted in three sessions of 50-60 minutes lessons, excluding the administration of pre-test and interview. A pre-test, consisting of 8 questions, was administered by the class teacher prior to intervention lessons with the purpose of identifying students' level of achievement in calculating percentage as they have learned the topic prior to this study. 
The intervention lessons were constructed with close reference to the learning objectives of percentage set by Cambridge IGCSE Mathematics syllabus for examination, with multiple percentage calculation used as examples. For each question, students were asked to work out the problem using their own preferred method, followed by introduction to the application of the Bubble Method to solve the problem.

Finally, the students were given post-test which consisted of the same questions as the pre-test questions to measure the effect of intervention on students performance.This was administered on the third session and the students were given the freedom to answer the post-test with any method they preferred. Paired-sample t-test between the pre- and post-test was carried out using the Statistical Package for the Social Science (SPSS) software to check if there exist a significant improvement due to the intervention. In addition, the association between Bubble Method and the students' achievement was measured by calculating the Pearson Chi-squared value.

For this study, a one-on-one semi-structured interview was conducted to explore the students' perspective on the effect of the bubble on their mental computation skill. To ensure the responses from the participants were captured, the researcher will use a voice recorder during the interview, suggested by Mills (2014) so that thorough analysis could be done.

Initially total of 12 out of 44 students were chosen for interview; 4 students from each class to represent their class. However, due to certain circumstances, only 3 students were interviewed for Class A and 4 students for each of the other two classes which made a total of 11 students. The students were selected based on the analysis of the pre-test and post-test.

The structure of the interview was centralised based on the following questions:

1) (a) Can you tell me about yourself as a mathematics student?

(b) How do you find mathematics? Easy, medium or difficult?

2) (a) Do you remember the Bubble Method I introduced during the intervention?

(b) Do you understand the Bubble Method?

(c) How do you find it?

3) (a) What can you understand by the word 'mental computation'?

(b) By comparing the Bubble Method and the usual method you used in calculating percentage, which one involves more mental computation if no calculators are allowed to be used?

(c) Do you think the Bubble Method enhance your mental computation skill?

4) (a) When you did the post-test, do you realise that the questions were the same as the pre-test?

(b) Do you remember how you perform in the pre-test?

(c) Do you think that have any effect on you performance in the post-test?

(d) If given more time in practicing answering questions using the Bubble Method, do you think you will perform better in the post-test?

The transcripts from the interview were coded and analysed according to the theme of the responses obtained, and at instances of responses to open questions, appropriate coding and making sense of the responses and connection to the research questions was done, as suggested by Lowe (2007).

\section{Result and Discussion}

From Table 1, the mean of test score for Class A decreased from 3.36 in the pre-test to 2.43 in the post-test a significance value of more than $0.05(\mathrm{p}=0.60)$. Hence, there is no evidence showing that the intervention had any effect on the post-test. The reason for this might be due to the level of the students' ability. The students from Class A consisted of low achievers and slow learners. Hence, the decrease in the mean value of pre-test to post-test for this class could be due to the students' lack of interest to study, or weak ability to grasp or fully utalised the bubble method concept at the given intervention time. Furthermore, the post-test was conducted 
during the last period of the school time during which these students might not give their best effort in attempting the test.

Table 1Paired sample t-test for Pre and Post Tests

\begin{tabular}{|c|c|c|c|c|c|c|}
\hline & & Mean & $\begin{array}{c}\text { Standard } \\
\text { Deviation }\end{array}$ & $\begin{array}{c}\text { Mean } \\
\text { Difference }\end{array}$ & t-value & $\begin{array}{l}\text { Significance } \\
\text { value }\end{array}$ \\
\hline \multirow{2}{*}{ Class A } & Pre & 3.36 & 1.008 & \multirow{2}{*}{-0.93} & \multirow{2}{*}{-2.06} & \multirow{2}{*}{0.60} \\
\hline & Post & 2.43 & 1.505 & & & \\
\hline \multirow{2}{*}{ Class B } & Pre & 6.75 & 1.055 & \multirow{2}{*}{0.83} & \multirow{2}{*}{4.02} & \multirow{2}{*}{0.002} \\
\hline & Post & 7.58 & 0.900 & & & \\
\hline \multirow{2}{*}{ Class C } & Pre & 5.44 & 1.917 & \multirow{2}{*}{0.95} & \multirow{2}{*}{1.84} & \multirow{2}{*}{0.84} \\
\hline & Post & 6.39 & 1.614 & & & \\
\hline
\end{tabular}

It can be seen that Class B was the only group with statistically significant difference between the mean in pretest and post-test $(\mathrm{p}<0.05)$, with an increase mean of 0.83 . Therefore, the intervention did offer some effect on the post-test result. To measure the size of the difference and the effect of the intervention, Cohen d's value was calculated. It was suggested by Cohen that if $d=0.2$, the effect is small, $d=0.5$ suggests moderate effect, and $d$ $=0.8$ suggest the effect is large. For Class B results, the calculated value of the effect size, $\mathrm{d}$, for this group was 1.16. Since this value was more than 0.80 , the effect size is large and this gives extra evidence that the intervention did improve the students' performance in calculating percentage for this class. The fact that this class consists of high achievers and fast learners could be the reason of the large effect. Furthermore, the class teacher informed the researcher that these students' mental computation skills were already good and possibly this intervention have a further positive impact on that mental computation ability.

The result for Class $\mathrm{C}$, shows some improvement after the intervention (mean increase if 0.95) but the difference was not statistically significant $(p>0.05)$. However, further analysis on calculating the effect size $(d=0.43)$ suggest that the intervention had moderate effect on the result since the value of $\mathrm{d}$ obtained was close to 0.5 . This moderate effect could be due to the level of the students' achievements that comprised of a combination of low and high achievers, thus the low results obtained by the low ability students might have affected the outcome and significance of the overall result.

Table 2 shows the number of students and the percentages of the number of students for each class comparing their performance and the method they chose to answer the post-test. Negative difference means that the students scored lower in the post-test than in the pre-test, positive difference means that the students scored higher in the post-test after the intervention and no difference means that the students scored the same mark in both pre-test and post-test. For Class A and Class C, we can see that majority of the students preferred Bubble Method compared to the usual method. As for Class B, equal number of students preferred either Bubble Method or usual method. However, those who chose mixed method also used Bubble Method to answer some of the questions. Hence, they also preferred Bubble Method to some extent. If this is the case, then majority of students from each class preferred Bubble Method compared to usual method.

Table 2Cross tabulation between pre-test and post-test score difference with method used in post-test according to their class

\begin{tabular}{cccc}
\hline Negative & No & Positive & \multirow{2}{*}{ Total } \\
Difference & Difference & Difference & \\
\hline
\end{tabular}




\begin{tabular}{|c|c|c|c|c|c|c|}
\hline \multirow{5}{*}{ Class A } & Usual Method & $\begin{array}{c}3 \\
(21.4 \%)\end{array}$ & $\begin{array}{c}0 \\
(0.0 \%)\end{array}$ & $\begin{array}{c}0 \\
(0.0 \%)\end{array}$ & $\begin{array}{c}3 \\
(21.4 \%)\end{array}$ & \multirow{5}{*}{$\begin{array}{c}14 \\
(100 \%)\end{array}$} \\
\hline & Bubble & 3 & 3 & 2 & 8 & \\
\hline & Method & $(21.4 \%)$ & $(21.4 \%)$ & $(14.3 \%)$ & $(57.1 \%)$ & \\
\hline & Mixed & 2 & 1 & 0 & 3 & \\
\hline & Method & $(14.3 \%)$ & $(7.1 \%)$ & $(0.0 \%)$ & $(21.4 \%)$ & \\
\hline \multirow{6}{*}{ Class B } & \multirow{2}{*}{ Usual Method } & 0 & 1 & 4 & 5 & \multirow{6}{*}{$\begin{array}{c}12 \\
(100 \%)\end{array}$} \\
\hline & & $(0.0 \%)$ & $(8.3 \%)$ & $(33.3 \%)$ & $(41.6 \%)$ & \\
\hline & Bubble & 0 & 1 & 4 & 5 & \\
\hline & Method & $(0.0 \%)$ & $(8.3 \%)$ & $(33.3 \%)$ & $(41.6 \%)$ & \\
\hline & Mixed & 0 & 2 & 0 & 2 & \\
\hline & Method & $(0.0 \%)$ & $(16.7 \%)$ & $(0.0 \%)$ & $(16.7 \%)$ & \\
\hline \multirow{6}{*}{ Class C } & & 0 & 1 & 5 & 6 & \multirow{6}{*}{$\begin{array}{c}18 \\
(100 \%)\end{array}$} \\
\hline & Usual Method & $(0.0 \%)$ & $(5.6 \%)$ & $(27.8 \%)$ & $(33.3 \%)$ & \\
\hline & Bubble & 2 & 0 & 6 & 8 & \\
\hline & Method & $(11.1 \%)$ & $(0.0 \%)$ & $(33.3 \%)$ & $(44.4 \%)$ & \\
\hline & Mixed & 2 & 0 & 2 & 4 & \\
\hline & Method & $(11.1 \%)$ & $(0.0 \%)$ & $(11.1 \%)$ & $(22.2 \%)$ & \\
\hline
\end{tabular}

Those who chose bubble method either in Class B or C, maintained their mark or increase their performance in the post-test result. Some students in class A and C perform worse in post-test when choosing the bubble methods. As suggested before, these students might be of the weak ability students who are yet to be able to attempt bubble method correctly.

The data from Table 2 can be further simplified by comparing the performance and the method chosen in the post-test by the participants as a whole without categorising them into classes. This data is shown in Table 3 .

Table 3 Cross tabulation between pre-test and post-test score difference with method used in post-test of the whole participants

\begin{tabular}{lcccc}
\hline & $\begin{array}{c}\text { Negative } \\
\text { Difference }\end{array}$ & No Difference & $\begin{array}{c}\text { Positive } \\
\text { Difference }\end{array}$ & Total \\
\hline Usual Method & 3 & 2 & 9 & 14 \\
& $(.8 \%)$ & $(4.5 \%)$ & $(20.5 \%)$ & $(31.8 \%)$ \\
\hline Bubble Method & 5 & 4 & 12 & 21 \\
& $(11.4 \%)$ & $(9.1 \%)$ & $(27.3 \%)$ & $(47.4 \%)$ \\
\hline \multirow{2}{*}{ Mixed Method } & 4 & 3 & 2 & 9 \\
& $(9.1 \%)$ & $(6.8 \%)$ & $(4.5 \%)$ & $(20.5 \%)$ \\
Total & 12 & 9 & 23 & 44 \\
& $(27.3 \%)$ & $(20.5 \%)$ & $(52.3 \%)$ & $(100 \%)$ \\
\hline
\end{tabular}

From Table 3, it can be seen that majority of the students preferred Bubble Method compared to the usual method as mentioned previously and approximately half of the total number of students improved in the posttest after the intervention. Out of these students, more than half had chosen either Bubble Method or mixed method. Using the previous assumption that those who chose mixed method also preferred Bubble Method to some extent, this might suggest that those who made improvements were the ones who used Bubble Method in the post-test, with $68 \%$ choosing either the bubble method or mixed method, $16 \%$ maintained their grade in the post-test, while $32 \%$ performed better after the intervention. 


\section{Student Interviews}

The participants of this study were of different achievers and hence, the process of selection based on their achievement tests was different for each class. From the interview with all 11 students, most of them agreed with the classification of their achievement level except for the high achievers, they all think that they were of average achievers instead of what had been told by their class teacher.

When the students were asked on their perspective on mathematics in general, two of them said that mathematics is easy with a lot of practice. The interview also revealed few areas of mathematics that some of the students had difficulties in: algebra, equations, formulae, and word problems. The students who had difficulties in doing word problems were either not good in understanding English or good in English language but had difficulties in extracting information from the word problem.

In terms of the students' perspective on the Bubble Method, majority of the interviewees found the Bubble method to be simple, easy, and straight forward method. However, four out of the eleven students said that the method was a little bit confusing and three of them were of the low achievers and preferred to use the usual method. This gives evidence that the low result in class A (and non-statistical significance of class C) may be due to the fact that the low ability students are not familiar or able to grasp the intervention concept in the short period of intervention, thuse causing them not to successfully attempt the post-test using the bubble method.

All of the students, except one, agreed that they realised that the pre-test and post-test consisted of the same questions. However, only three claimed that there was an effect on their post-test performance. Five of the students said that even if they knew the questions were the same, it had no effect on their performances in the post-test and the rest of the students were not sure whether it affected their performances.

To conclude the interview findings, 10 out of the 11 students definitely agreed that the Bubble Method enhanced their computational skills and required them to use the skills more than the usual method.

\section{Conclusion}

The summary of the results and findings from the data collected are presented according to the research questions of this study.

Research Question 1: What is the relationship between students' achievement and the use of Bubble Method in calculating percentage?

From the analysis of the pre- and post-test results, there is evidence that supports the intervention of using Bubble Method to calculate percentage have positive signifiant impact on high ability students' performance. On the other hand, majority of the students who improved in the post-test chose the Bubble Method to calculate percentage and from the students' sample work, there is some evidence showing that the Bubble Method helps to avoid certain misconception and careless mistake in calculating percentage, hence, enhancing the students' performance in solving percentage problems.

In addition, from the result of the interview with the students' who chose Bubble Method in the post-test revealed that they feel more confident in calculating percentage using the Bubble Method compared to the usual method. Drop in performance of low ability students (in class A, possibly some in Class C) indicates that these students might not be able to successfully attempt question using the bubble method due to lack of familiarity or grasping the concept. 
Research Question 2: What are the students' perception of Bubble Method in terms of enhancing their mental computation and calculating percentage?

Based on the interview with the students of this study, all of them either agreed or somewhat agreed that the Bubble Method enhanced their mental computational skill and required them to use more of the skill compared to the usual method. In terms of using the Bubble Method to calculate percentage, majority of the students found that the method was interesting, straight forward, and easy to understand. On the other hand, few of the students pointed out that the method is confusing, time consuming and a lot of things to work on and thus might require more time and practice to master the concept.

\section{Implications}

Even though the statistical data obtained in this study did not offer enough evidence to suggest that Bubble Method improve the students' performance in calculating percentage in general, evidence do support that bubble method is significant in the improvement in performance of high achievers. This makes bubble method a possible great follow-up activity or reinforcement for learning purposes in these group of students.

While most found the bubble method interesting, straightforward and easy to understand, some also pointed out method is confusing, time consuming and involves multiple component. Result in the weak ability students indicated that more practice and time might be needed for students to fully grasp the concept and successfully attempt them.

Bubble method can be used not only for the purpose of improving students' mental computation, but also as an alternative method for calculating percentage, as observed in some of the students' sample work. Some showed that they have more confidence in calculating percentage using Bubble Method and this method help reduce the common mistakes made by students in calculating percentage.

\section{Recommendations}

Since this study is a short action research study, it can be repeated where the percentage lesson using the Bubble Method can be conducted for a longer period of time. With longer period of time and regular practice, the students would be more familiarised in using the Bubble Method especially for the low achievers who are slow learners. For future research, it would be good to try introducing the Bubble Method before the usual method to see if it would affect the preferences of method in calculating percentage. Alternatively, introducing bubble method in theprimary/elementary level might have that added benefit of early familiarsation and development of mental computation.

\section{References}

Cruickshank, D. R., Metcalf, K. K., and Jenkins, D. B., 2009, The Act of Teaching (5th ed.) (Blacklick, Ohio: McGraw).

Hartnett, J. E., 2007, Categorisation of Mental Computation Strategies to Support Teaching and to Encourage Classroom Dialogue. In J.Watson\& K. Beswick (Eds). Proceedings 30th annual conference of the Mathematics Education Research Group of Australasia - Mathematics: Essential Research, Essential Practice, Hobart, Tasmania, pp. 345-352.

Kachapova, F. andKachapov, I., 2012, Percentage problems in bridging courses. International Journal of Mathematical Education in Science and Technology, 43(5), 654-663. 
Lowe, M., 2007, Beginning Research: A Guide for Foundation Degree Students (New York, NY: Routledge).

McIntosh, A., 2006, Mental computation of school-aged students: Assessment, performance levels and common errors. In C. Bergsten \& B. Grevholm (Eds.). Proceedings of MADIF 5, the 5th Swedish Mathematics Education Research Seminar - Developing and Researching Quality in Mathematics Teaching and Learning, Malmö, Sweden, pp. 136-145.

McIntosh, A., and Dole, S., 2000, Number sense and mental computation: Implications for numeracy. In Australian Council for Educational Research (ACER), Proceedings Research Conference - Improving Numeracy Learning, Brisbane, Australia, pp. 34-37.

Mills, G. E., 2014, Action Research: A Guide for the Teacher Researcher (Australia: Pearson Education).

Ministry of Education, 2013, The National Education System for the $21^{\text {st }}$ Century: SPN21(Revised ed.) (Berakas: Ministry of Education).

Parker, M., andLeinhardt, G., 1995, Percent: A privileged proportion. Review of Educational Research, 65(4), 421-481.

Reys, R. E., Reys, B. J., Nohda, N., andEmori, H., 1995, Mental computation performance and strategy use of Japanese students in grades 2, 4, 6 and 8. Journal for Research in Mathematics Education, 26(4), 304-326.

Rogers, A., 2009, Mental Computation in the Primary Classroom. In R. P. Hunting, T. Fitzpatrick, J. A. Milne, D. J. Itter, D. L. Martin, T. M. Mills, C. T. Lenard (Eds.). Proceedings of the Mathematical Association of Victoria 46th Annual Conference - Mathematics of Prime Importance, Brunswick, Victoria, pp. 190-199.

Thompson, J., 2011, Bubble method - for finding percentages of any number | Skills Workshop. http://www.skillsworkshop.org/resources/bubble-method-finding-percentages-any-number

Watson, J.and English, L. D., 2013, The power of percent. Australian Primary Mathematics Classroom, 18(4), pp. 14-18.

White, P., Mitchelmore, M., Wilson, S., andFaragher, R., 2009, Critical Numeracy and Abstraction: Percentages. Australian Primary Mathematics Classroom, 14(1), 4-8.

Wiggly, A., 2008, Last chant for times tables. TES Newspaper. https://www.tes.co.uk/article.aspx?storycode=23573 